\title{
EVIDENCE SUPPORTING THE OCCURRENCE AND THE ECOLOGICAL IMPLICATION OF GIANT MOTTLED EEL, ANGUILLA MARMORATA (ACTINOPTERYGII: ANGUILLIFORMES: ANGUILLIDAE), FROM SABAH, BORNEO ISLAND
}

\author{
Li Lian WONG ${ }^{1}$, Siti Raudah ABDUL KADIR ${ }^{2}$, Rabi Atun ADAWIAH ABDULLAH ${ }^{1}$, Charlie \\ Albert LASUIN ${ }^{3}$, Kok Onn KWONG ${ }^{4}$, and Takaomi ARAI ${ }^{5 *}$ \\ ${ }^{1}$ Institute of Tropical Aquaculture, Universiti Malaysia Terengganu, Kuala Terengganu, Terengganu, Malaysia \\ ${ }^{2}$ Institute of Oceanography and Environment, Universiti Malaysia Terengganu, Kuala Terengganu, Terengganu, \\ Malaysia \\ ${ }^{3}$ Faculty of Business, Economics and Accountancy, Universiti Malaysia Sabah, Kota Kinabalu, Sabah, Malaysia \\ ${ }^{4}$ School of Biological Sciences, Universiti Sains Malaysia, Minden, Penang, Malaysia \\ ${ }^{5}$ Environmental and Life Sciences Programme, Faculty of Science, Universiti Brunei Darussalam, Brunei Darussalam
}

Wong L.L., Abdul Kadir S.R., Adawiah Abdullah R.A., Lasuin C.A., Kwong K.O., Arai T. 2017. Evidence supporting the occurrence and the ecological implication of giant mottled eel, Anguilla marmorata (Actinopterygii: Anguilliformes: Anguillidae), from Sabah, Borneo Island. Acta Ichthyol. Piscat. 47 (1): 73-79.

\begin{abstract}
Although tropical anguillid eels account for two-thirds of all species in the genus Anguilla, the information on the species diversity, geographic distribution, and life histories of the tropical eels is very limited. Recent studies suggested that accurate species identification in the tropical anguillid eels needs a validation by molecular genetic analysis after morphological observation. Two anguillid eels found in Sabah, Borneo Island, were firstly identified as Anguilla marmorata Quoy et Gaimard, 1824 using morphological analysis and further analysis of mitochondrial 16S ribosomal RNA (16S rRNA) sequences confirmed the morphological species identification. The presently reported study represents the first description of A. marmorata in Sabah, Borneo Island. One-year survey suggests that representatives of $A$. marmorata found in the region might belong to the North Pacific population in the westernmost distribution.
\end{abstract}

Keywords: tropical anguillid eel, diadromous fish, geographical distribution, marbled eel, Madagascar mottled eel, giant long-finned eel, tropical biodiversity

The anguillid eels of the genus Anguilla Schrank, 1798 are widely distributed throughout the world. These eels have a catadromous life history, migrate between inland waters and coastal growth habitats, and have offshore spawning. Nineteen species/subspecies of freshwater eels have been reported worldwide, including 13 from tropical regions (Ege 1939, Watanabe et al. 2013, Arai 2016). Of the latter, seven species occur in the western Pacific around Indonesia and Malaysia (Ege 1939, Arai 2016). Molecular phylogenetic research on freshwater eels has revealed that tropical eels are the most basal species originating in the Borneo Island and that freshwater eels radiated out from the tropics to colonize the temperate regions (Minegishi et al. 2005). Tropical freshwater eels must be more closely related to the ancestral form than their temperate-climate counterparts. Thus, studying the biological aspects of tropical eels provide clues for understanding the nature of primitive forms of catadromous migration in freshwater eels and how the large-scale migration of temperate species became established.

The recent drastic decline of glass eel recruitment in Europe and East Asia has caused serious problems in eel stock to sustainable levels of adult abundance (Arai 2014a). Tropical eels are considered a major target species to compensate the high demand of eel resources. Recently, freshwater eel biology such as species composition, distribution and life history has been gradually accumulated in tropical eel species in Peninsular Malaysia 
(West Malaysia) (Arai et al. 2012, 2015, Arai and Chino 2013, Arai 2014b, Abdul Kadir et al. 2015, Arai and Wong 2016). The identification of eels at the species level using solely visual observation is suggested to be difficult because of the similarities and overlapping morphological characteristics in eels, particularly tropical anguillids (Arai et al. 2015, Arai 2016, Arai and Wong 2016). Furthermore, such information about the geographical distribution, species composition, and life history is available in the limited area and little information is still available for many tropical eels across the Indo-Pacific region.

In the presently reported study, we surveyed and collected two anguillid eels during a one-year sampling in Sabah, Borneo Island. These eels were subjected to identification using both morphological analyses and mitochondrial 16S ribosomal RNA (16S rRNA) sequence analyses. This paper describes the first confirmed record of a tropical anguillid eel, Anguilla marmorata Quoy et Gaimard, 1824, from Borneo Island. We also discussed the ecological implication and importance of the occurrence of A. marmorata in the region.

Eels and morphological analysis. During one-year survey between August 2015 and July 2016, two anguillid eels were caught by a fishing rod and line, using sago worms as bait by local people in the Papar River, Papar District, Sabah, Borneo Island, East Malaysia on 23 March and 2 May 2016 (Fig. 1, Table 1). The Papar River with a total flow length of approximately $60 \mathrm{~km}$ originates from the Crocker Range and flows towards a large floodplain and discharges into the South China Sea (Fig. 1). The Papar River has several tributaries, particularly in the middle and upper reaches and approximately $85 \%$ of the floodplain area is flat alluvial, with the remainder either sandy ground or mangrove swamp (Chai et al. 2012). The Papar River floodplain is an important area for paddy growing and agriculture plantation, however its potential is limited by the loss of arable land caused by accelerated flooding and sedimentation (Chai et al. 2012). There are two monsoon regimes, the southwest monsoon (May to September) and the northeast monsoon (November to March). The northeast monsoon brings heavy rainfall and the southwest monsoon normally signifies relatively drier weather. Two eels were collected in the freshwater area where the eel inhabits were in deep and dark holes covered with wilted leaves from the trees surrounding the area of the river.

The external morphometric characteristics were measured following Ege (1939) and Watanabe et al. (2004), and the data are shown in Table 1. The fin difference index (FDI), which is the distance between the verticals from beginning of the dorsal fin $(Z)$ to the anus (ano-dorsal length) relative to the total length (TL) (Ege 1939), was calculated as follows:

$$
\mathrm{FDI}=100 Z \cdot \mathrm{TL}^{-1}
$$

The sex of each eel was determined by visual and histological observations of the gonads. Whole gonad weight was measured, and gonadosomatic

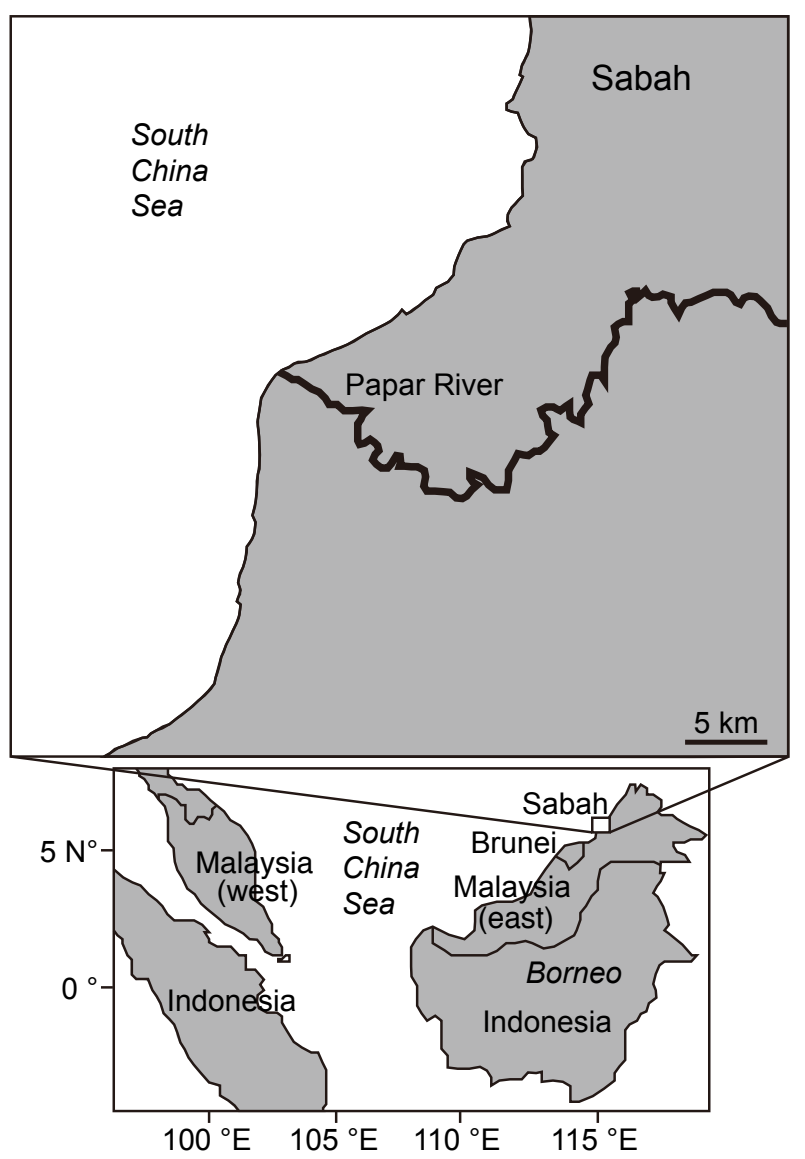

Fig. 1. Eel sampling site in the Papar River, Manggis, Sabah, Borneo Island (East Malaysia)

index (GSI; percent relative gonad weight to BW) was subsequently calculated.

Histology analysis. The histology of all specimens was examined. Fragments from the middle region of one gonad were fixed in formalin for histological analysis. Tissue fragments were prepared for resin and routine paraffin embedding. Resin blocks were processed routinely and paraffin blocks were sectioned at $5 \mu \mathrm{m}$ and stained with haematoxylin-eosin for histological observation. Histology classifications in female and male were according to Arai (2014c) and Arai et al. (2016).

Molecular species identification. DNA was extracted from dorsal fin clip of each specimen using Gentra Puregene Tissue Kit (QIAGEN, USA), according to the manufacturer's instruction. Total DNA concentration and quality was quantified using BioPhotometer Plus spectrophotometer (Eppendorf, Germany). PCR amplification for $16 \mathrm{~S}$ rRNA gene using primer sets from Palumbi et al. (1991); L2510: 5'CGC CTG TTT ATC AAA AAC AT 3' and H3080: 5' CCG GTC TGA ACT CAG ATC ACG T 3' was conducted according to Arai and Wong (2016). PCR amplicons were purified using QIAquick ${ }^{\circledR}$ PCR Purification Kit (QIAGEN, USA), labelled with BigDye Terminator v.3.1 Cycle Sequencing Kit (Applied Biosystems Inc., USA) and sequenced bi-directionally on an ABI PRISM 3730xl Genetic Analyzer. Generated 
Table 1

Morphometric characters of Anguilla marmorata collected in Sabah, Borneo Island

\begin{tabular}{|c|c|c|}
\hline \multirow{2}{*}{ Parameter } & \multicolumn{2}{|c|}{ Specimen } \\
\hline & SB-1 & SB-2 \\
\hline Total length (TL) [mm] & 1309.0 & 688.0 \\
\hline Body weight $[\mathrm{g}]$ & 6500.0 & 817.0 \\
\hline Gonad weight $[\mathrm{g}]$ & 190.7 & 0.32 \\
\hline Head length (HL) [mm] & 172.0 & 100.0 \\
\hline Predorsal length (PD) [mm] & 368.0 & 200.0 \\
\hline Preanal length $(\mathrm{PA})[\mathrm{mm}]$ & 570.0 & 324.0 \\
\hline Distance between verticals through anus and origin of dorsal fin (AD) [mm] & 202.0 & 124.0 \\
\hline Predorsal length without head length $(\mathrm{PDH})[\mathrm{mm}]$ & 196.0 & 100.0 \\
\hline Preanal length without head length (TR) [mm] & 398.0 & 224.0 \\
\hline Distance from tip of lower jaw to corner of mouth (LG) [mm] & 63.7 & 26.0 \\
\hline Distance from perpendicular through eye centre (DEG) [mm] & 20.7 & 6.5 \\
\hline Length of intermaxillary-vomerine band (LV) [mm] & 33.1 & 19.3 \\
\hline Length of left maxillary band (LM) [mm] & 44.5 & 23.4 \\
\hline Number of teeth of mid part of maxillary band (NMM) [mm] & 2.0 & 2.0 \\
\hline Width of mid part of maxillary band (WMM) [mm] & 2.8 & 1.4 \\
\hline Fin difference index (FDI) $[\%]$ & 15.0 & 18.0 \\
\hline $\mathrm{PA} \div \mathrm{TL}[\%]$ & 43.5 & 47.1 \\
\hline $\mathrm{HL} \div \mathrm{TL}[\%]$ & 13.0 & 15.0 \\
\hline $\mathrm{TR} \div \mathrm{TL}[\%]$ & 30.0 & 33.0 \\
\hline $\mathrm{PDH} \div \mathrm{TL}[\%]$ & 15.0 & 15.0 \\
\hline Patten of colour marking of skin & Variegated & Variegated \\
\hline Sex & Female & Female \\
\hline Gonadosomatic index [\%] & 2.93 & 0.04 \\
\hline Gonad maturity stage & $\mathrm{V}$ & I \\
\hline
\end{tabular}

sequence tracefiles were manually edited and assembled using SeqMan Pro application in DNASTAR version 6.0 (DNASTAR Inc., USA). The contig sequences were compared for percentage similarity with the reference sequences in the GenBank using BLAST search. The sequences were submitted to GenBank with accession numbers KX832900-KX832901.

Morphological implications. Two eel samples had skin with variegated markings (Figs. 2A, 2B). Furthermore, both eels had narrow maxillary bands of teeth with number of teeth of mid part of maxillary band (2) (Figs. 2C, 2D, Table 1) and 15\%-18\% of FDI (Table 1).

Two eel samples were assigned into the second group of the genus Anguilla: Anguilla bengalensis bengalensis (Gray, 1831); Anguilla bengalensis labiata (Peters, 1852); Anguilla marmorata; Anguilla reinhardtii Steindachner, 1867; based on their variegated skin and narrow maxillary bands of teeth (Ege 1939, Arai 2016, Arai and Wong 2016) (Table 2). However, Anguilla celebesensis (Kaup, 1856) and Anguilla interioris (Whitley, 1938) belong to the first group of the genus Anguilla with their variegated skin and broad maxillary bands of teeth (Table 2). Therefore, the eel samples were not assigned into them.

The geographical distribution of anguillids in combination with key morphological characteristics helped to identify the eel species. Representatives of the second group, A. bengalensis labiata and A. reinhardtii occur in the mid-south-eastern region of Africa and eastern Australia and Tasmania, respectively (Ege 1939). Therefore, both of these species were not considered when species specificity of the samples was assessed in the presently reported study. The FDI of the other two species, A. bengalensis bengalensis and A. marmorata was studied further. According to the key morphological characteristics used for identification (Ege 1939, Watanabe et al. 2004), the FDI of $A$. marmorata is in the range of 12 to 20, higher than that of $A$. bengalensis bengalensis, which is in the range of 8 to 13 (Ege 1939, Arai 2016). Based on the FDI of 15 (SB-1) and 18 (SB-2), these eels were further considered as A. marmorata.

Both eels of SB-1 and SB-2 were females based on the visual observation of their gonads and their histology data (Fig. 3, Table 1). Interestingly, the eel specimen of SB-1 had high GSI (2.93\%) and final stage of maturation of stage V (Fig. 3, Table 1). It suggests that the eel attained the condition to commence a downstream migration to open ocean for spawning. The eel specimen of SB-2 had the GSI value of 0.04 and the maturation stage was stage I suggesting that the eel was still in the immature stage.

Species validation by molecular genetic analysis. Molecular identification based on 16 rRNA gene has confirmed that both specimens are A. marmorata with $99 \%$ maximum identity matches with reference data in GenBank. 

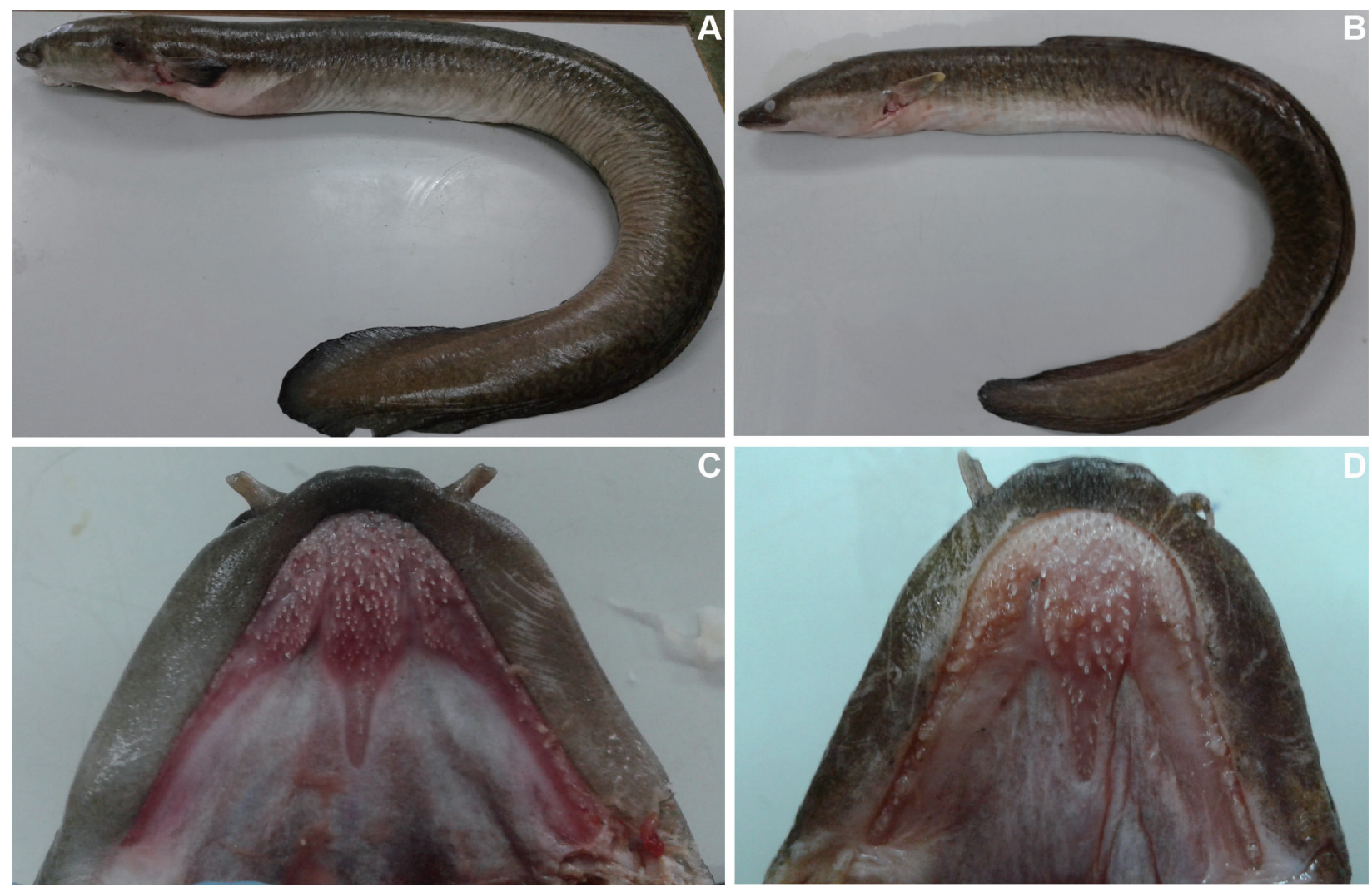

Fig. 2. Anguilla marmorata collected in the Papar River, Papar District, Sabah, Borneo Island (East Malaysia); SB-1, A. marmorata (1309 mm TL) (A); SB-2, A. marmorata (688 mm TL) (B); Narrow maxillary bands of teeth of SB-1 (C); Narrow maxillary bands of teeth of SB-2 (D); DNA was extracted from dorsal fin clip of each specimen, and therefore posterior dorsal fin of each specimen is lacking

Table 2

Comparison of key morphometric characters of different eel species of the genus Anguilla possibly entering rivers in Sabah region

\begin{tabular}{lccccccc}
\hline \multirow{2}{*}{ Parameter } & \multicolumn{7}{c}{ Eel species/specimen } \\
\cline { 2 - 8 } & SB-1 & SB-2 & AB & AM & AC & ABB & AI \\
\hline PA $\div$ TL [\%] & 43.5 & 47.1 & $38.0-44.0$ & $39.0-49.0$ & $37.0-45.0$ & $37.5-43.0$ & $38.0-46.0$ \\
HL $\div$ TL [\%] & 13.0 & 15.0 & $12.0-15.0$ & $11.0-18.0$ & $11.0-17.0$ & $12.0-14.0$ & $12.0-17.0$ \\
TR $\div$ TL [\%] & 30.0 & 33.0 & $25.0-30.0$ & $25.0-34.0$ & $25.0-30.0$ & $25.5-29.0$ & $25.0-28.5$ \\
PDH $\div$ TL [\%] & 15.0 & 15.0 & $13.0-18.0$ & $8.0-18.0$ & $13.0-21.0$ & $12.0-18.0$ & $10.0-22.0$ \\
LV $\div$ LM [\%] & 74.0 & 82.0 & $75.0-105.0$ & $60.0-93.0$ & $80.0-116.0$ & $67.5-97.5$ & $75.0-105.0$ \\
FDI [\%] & 15.0 & 18.0 & $9.0-13.0$ & $12.0-20.0$ & $6.0-14.0$ & $8.0-13.0$ & $7.0-15.0$ \\
WMM $\div$ LM [\%] & 6.0 & 6.0 & $4.0-11.0$ & $7.0-12.5$ & $14.0-25.5$ & $7.0-13.0$ & $14.0-21.5$ \\
DEG $\div$ LG & 32.0 & 25.0 & $1.25-15.0$ & $0.0-15.0$ & $2.5-20.0$ & $4.0-10.0$ & $12.0-20.0$ \\
Skin pattern & VAR & VAR & NVAR & VAR & VAR & VAR & VAR \\
\hline
\end{tabular}

Specimens SB-1 and SB-2 represent Anguilla marmorata from the presently reported study; data in all other columns were taken from Ege (1939); $\mathrm{AB}=$ Anguilla borneensis, $\mathrm{AM}=$ Anguilla marmorata, $\mathrm{AC}=$ Anguilla celebesensis $\mathrm{Kaup}, 1856, \mathrm{ABB}=$ Anguilla bengalensis bengalensis, $\mathrm{AI}=$ Anguilla interioris Whitley, 1938; $\mathrm{PA}=$ preanal length, $\mathrm{TL}=$ total length, $\mathrm{HL}=$ head length, $\mathrm{TR}=$ preanal length without head length, $\mathrm{PDH}=$ predorsal length without head length, $\mathrm{LV}=$ length of intermaxillary-vomerine band, $\mathrm{LM}=$ length of left maxillary band, FDI = fin difference index, WMM = width of mid part of maxillary band, DEG = distance from perpendicular through eye centre, Skin pattern $=$ pattern of colour marking of skin, VAR $=$ variegated, NVAR $=$ non variegated.

Two eels from Sabah in Borneo were firstly identified several reports had described presence of the eel in Sabah, as Anguilla marmorata based on their morphological all these publications did not meet the requirements of and molecular genetic analyses. The current study is the the valid species identification reported in the presently first description of the occurrence and distribution of reported study. The findings from previous studies have A. marmorata in Borneo (East Malaysia) identified both by suggested that tropical eel species identification could morphological and molecular genetic analyses. Although be accurately validated by molecular genetic analysis 

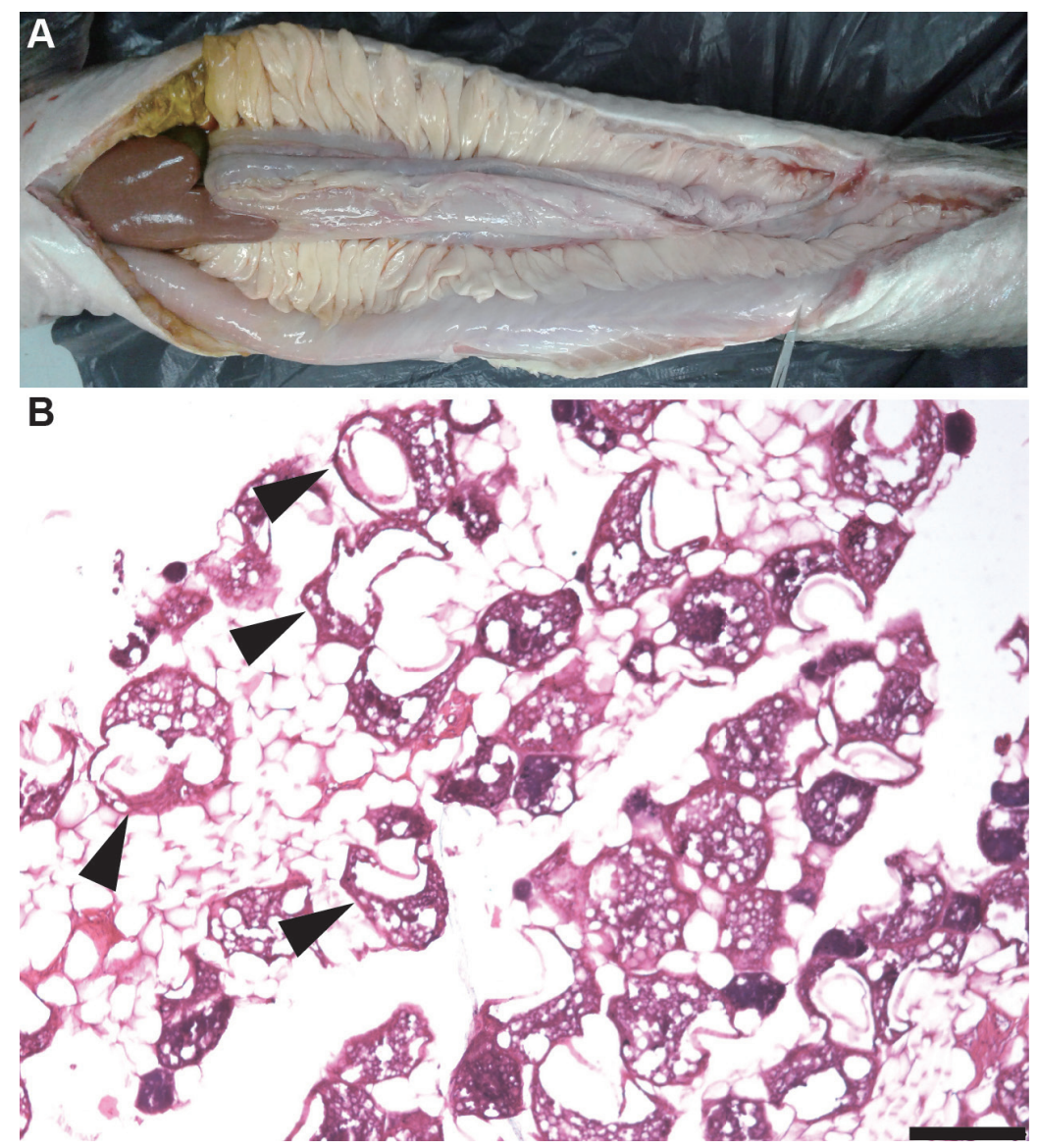

Fig. 3. Gonadal (A) and histological (B) morphologies of spawning-condition tropical freshwater eels Anguilla marmorata (1309 mm in TL) that was collected in March 2016; The gonadal histology of Stage V (B) showed mid-vitellogenic oocytes (arrows) in the final preparation for spawning; Scale bar: $100 \mu \mathrm{m}$

after morphological observation (Arai et al. 2015, Arai and Wong 2016). In previous studies, A. marmorata was reported to occur in Peninsular Malaysia (West Malaysia) (Ahmad and Lim 2006, Azmir and Samat 2010). After a thorough morphological re-examination by Ahmad and Lim (2006) of one formalin-preserved sample previously identified as $A$. marmorata, was subsequently identified as $A$. bengalensis bengalensis based on the value of 9 in the FDI (Arai 2014b). The species misidentification in the previous study may have been due to an insufficient morphological characteristic analysis. In fact, the difficulty in distinguishing both $A$. marmorata and A. bengalensis bengalensis is augmented by their overlapping morphological characteristics, which cause further identification ambiguities. Furthermore, the number of anguillid eels found in Peninsular Malaysia were identified using a morphological analysis and that identification was further validated as Anguilla bengalensis bengalensis by an analysis of the eels' mitochondrial cytochrome oxidase subunit I (COI) sequences and 16S ribosomal RNA (16S rRNA) sequences (Arai et al. 2015, Arai and Wong 2016). Thus, comprehensive morphological identification may be strengthened by the integration of molecular marker analyses to further validate the true identity of a species.

During the year-round survey, we could collect only two specimens of Anguilla marmorata in Sabah. This limited number of eels suggests that the study site might be out of the species main distribution region. A study on the population structure of the giant mottled eel, A. marmorata (see Minegishi et al. 2008), suggested that this species has a multiple structure covering populations distributed in the following areas:

- The North Pacific (from Japan to Sulawesi);

- The South Pacific (from Papua New Guinea to Tahiti);

- The Indian Ocean (from Sumatra to Madagascar);

- Guam (including Micronesia).

Based on the geographical location of Sabah and oceanic current in the region, A. marmorata from Sabah might belong to the North Pacific population (Fig. 4). The western North Pacific where is the spawning ground of the Japanese eel $A$. japonica, is suggested to be a possible spawning area for A. marmorata in the North Pacific population (Arai et al. 2002, Tsukamoto et al. 2011) (Fig. 4). Anguilla marmorata in Sabah might originate from spawning areas in the western North Pacific. However, the distance between the spawning area and recruitment area in Sabah is considerably longer than the distance from other distribution areas in the North Pacific population (Fig. 4), therefore the abundance of the specimens that reach Sabah might be quite low. This would make $A$. marmorata difficult to discover in the area. One specimen of $A$. marmorata (SB-1) showed the final 


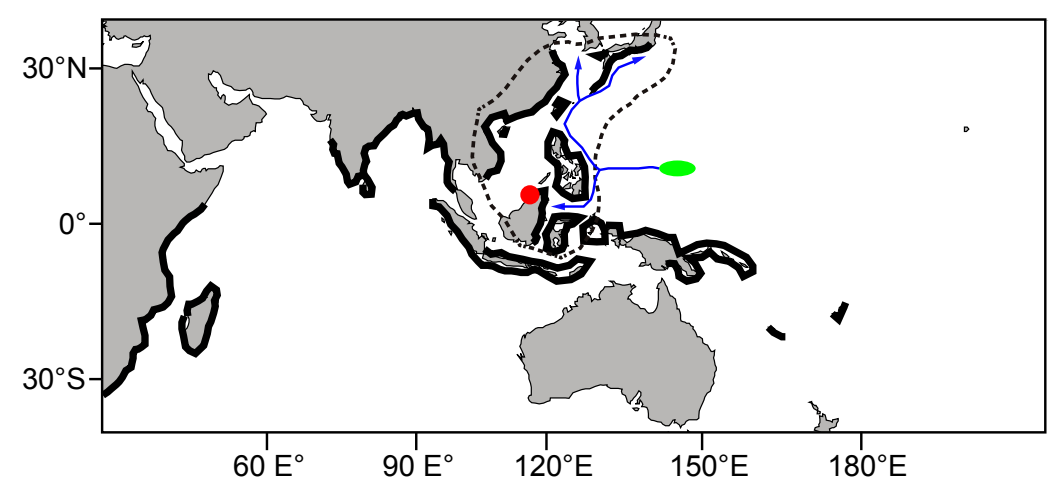

Fig. 4. Map showing the distribution range of Anguilla marmorata (thick lines on coastlines) by Ege (1939) and the North Pacific population found by the genetic analysis of $A$. marmorata by Minegishi et al. (2008) with a dotted line; The location of the offshore spawning area of A. marmorata in North Pacific population (green ellipse) with the oceanic currents (blue lines) from the spawning area is shown; Red circle indicates the sampling site in the Papar River, Papar District, Sabah, Borneo Island (East Malaysia)

stage of maturation and it might start (have just started) downstream migration for spawning to the western North Pacific. The finding suggests that the eel from the westernmost distribution of the North Pacific population might be able to contribute the reproduction. Further continuous field sampling should be undertaken, in order to better understand the details of diversity, distribution and life history of the tropical anguillid eels.

\section{ACKNOWLEDGEMENTS}

We are grateful to Jasman Tuyon for his kind assistance with the field survey. The authors are also grateful to South China Sea Repository and Reference Centre, School of Fundamental Sciences and Institute of Tropical Aquaculture in Universiti Malaysia Terengganu for the kind assistance with the laboratory work. This study was financially supported by the Ministry of Higher Education of Malaysia under the Fundamental Research Grant Scheme (Vot No. 59406) and by Universiti Brunei Darussalam under the Competitive Research Grant Scheme (Vot No. UBD/OVACRI/CRGWG(003)).

\section{REFERENCES}

Abdul Kadir S.R., Abdul Rasid M.H.F., Wong L.L., Kwong K.O., Arai T. 2015. First record of albinism in a tropical anguillid eel Anguilla bengalensis bengalensis from Malaysia. Marine Biodiversity Records 8: e114.

DOI: $10.1017 / \mathrm{S} 1755267215000950$

Ahmad A., Lim K.K.P. 2006. Inland fishes recorded from the Langkawi Islands, Peninsular Malaysia. Malaysian Nature Journal 59 (1): 103-120.

Arai T. 2014a. Do we protect freshwater eels or do we drive them to extinction? SpringerPlus 3: 534.

DOI: $10.1186 / 2193-1801-3-534$

Arai T. 2014b. First record of a tropical mottled eel, Anguilla bengalensis bengalensis (Actinopterygii: Anguillidae) from the Langkawi Islands, Peninsular Malaysia, Malaysia. Marine Biodiversity Records 7: e38.

DOI: $10.1017 / \mathrm{S} 1755267214000426$
Arai T. 2014c. Evidence of local short-distance spawning migration of tropical freshwater eels, and implications for the evolution of freshwater eel migration. Ecology and Evolution 4 (19): 3812-3819.

DOI: $10.1002 /$ ece 3.1245

Arai T. 2016. Taxonomy and distribution. Pp. 1-20. In: Arai T. (ed.) Biology and ecology of anguillid eels. CRC Press, Boca Raton, FL, USA.

Arai T., Abdul Kadir S.R., Chino N. 2016. Year-round spawning by a tropical catadromous eel Anguilla bicolor bicolor. Marine Biology 163 (2): 1-7. DOI: $10.1007 / \mathrm{s} 00227-015-2792-8$

Arai T., Chin T.C., Kwong K.O., Siti Azizah M.N. 2015. Occurrence of the tropical eels, Anguilla bengalensis bengalensis and Anguilla bicolor bicolor in Peninsular, Malaysia and implications for eel taxonomy. Marine Biodiversity Records 8: e28. DOI: $10.1017 / \mathrm{S} 1755267215000056$

Arai T., Chino N. 2013. Timing of maturation of a tropical eel, Anguilla bicolor bicolor in Malaysia. Journal of Applied Ichthyology 29 (1): 271-273. DOI: $10.1111 /$ jai.12040

Arai T., Chino N., Zulkifli S.Z., Ismail A. 2012. Notes on the occurrence of the tropical eel Anguilla bicolor bicolor in Peninsular Malaysia, Malaysia. Journal of Fish Biology 80 (3): 692-697.

DOI: $10.1111 /$ j.1095-8649.2011.03154.x

Arai T., Marui M., Miller M.J., Tsukamoto K. 2002. Growth history and inshore migration of the tropical eel, Anguilla marmorata, in the Pacific. Marine Biology 140 (2): 309-316.

DOI: $10.1007 / \mathrm{s} 002270100699$

Arai T., Wong L.L. 2016. Validation of the occurrence of the tropical eels, Anguilla bengalensis bengalensis and A. bicolor bicolor at Langkawi Island in Peninsular Malaysia, Malaysia. Tropical Ecology 57 (1): 23-31.

Azmir I.A., Samat A. 2010. Diversity and distribution of stream fishes of Pulau Langkawi, Malaysia. Sains Malaysiana 39 (6): 869-875.

Chai J. Frachisse J., Golingi T., Ku F., Lim W. 2012. Management plan for river sand mining in Sg. Papar 
and Sg. Kimanis. Environment Protection Department, DHI Water and Environment (M) Sdn Bhd, Malaysia.

Ege V. 1939. A revision of the genus Anguilla Shaw. Dana Report 16: 8-256.

Minegishi Y., Aoyama J., Inoue J.G., Miya M., Nishida M., Tsukamoto K. 2005. Molecular phylogeny and evolution of the freshwater eels genus Anguilla based on the whole mitochondrial genome sequences. Molecular Phylogeny and Evolution 34 (1): 134-146. DOI: 10.1016/j.ympev.2004.09.003

Minegishi Y., Aoyama J., Tsukamoto K. 2008. Multiple population structure of the giant mottled eel Anguilla marmorata. Molecular Ecology 17: 3109-3122.

DOI: $10.1111 / \mathrm{j} .1365-294 X .2008 .03822 . x$

Palumbi S., Martin A., Romano S., McMillan W., Stice L., Grabowski G. 1991. The simple fool's guide to PCR. Version 2. Department of Zoology and Kewalo Marine Laboratory, Honolulu, HI, USA.
Tsukamoto K., Chow S., Otake T., Kurogi H., Mochioka N., Miller M.J., Aoyama J., Kimura S., Watanabe S., Yoshinaga T., Shinoda A., Kuroki M., Oya M., Watanabe T., Hata K., Ijiri S., Kazeto Y., Nomura K., Tanaka H. 2011. Oceanic spawning ecology of freshwater eels in the western North Pacific. Nature Communications 2: article 179 .

DOI: $10.1038 /$ ncomms 1174

Watanabe S., Aoyama J., Hagihara S., Ai B., Azanza R.V., Tsukamoto K. 2013. Anguilla huangi Teng, Lin, and Tzeng, 2009, is a junior synonym of Anguilla luzonensis Watanabe, Aoyama, and Tsukamoto, 2009. Fisheries Science 79 (3): 375-383.

DOI: $10.1007 / \mathrm{s} 12562-013-0620-\mathrm{y}$

Watanabe S., Aoyama J., Tsukamoto K. 2004. Reexaminationof Ege's (1939) use of taxonomic characters of the genus Anguilla. Bulletin of Marine Science 74 (2): 337-351.

Received: 17 September 2016 Accepted: 15 December 2016 Published electronically: 31 March 2017 